\title{
Effectiveness and use of prophylactic antibiotics in elective and emergency caesarean section at tertiary care hospital
}

\author{
K. Rama Lingam', Hari Babu Ramineni' ${ }^{2 *}$, Shaik Gulshan Firdous², P. Yamuna², B. Madhuri², \\ D. N. S. S. Chidrupi ${ }^{2}$
}

\begin{abstract}
${ }^{1}$ Department of Obstetrics and Gynecology, NRI Medical College and Hospital, Guntur, Andhra Pradesh, India ${ }^{2}$ Department of Pharmacy Practice, Chebrolu Hanumaiah Institute of Pharmaceutical Sciences, Chowdavaram, Guntur, Andhra Pradesh, India
\end{abstract}

Received: 28 February 2020

Accepted: 30 March 2020

*Correspondence:

Dr. Hari Babu Ramineni,

E-mail: haris760@gmail.com

Copyright: (c) the author(s), publisher and licensee Medip Academy. This is an open-access article distributed under the terms of the Creative Commons Attribution Non-Commercial License, which permits unrestricted non-commercial use, distribution, and reproduction in any medium, provided the original work is properly cited.

\begin{abstract}
Background: Post-operative infections in obstetrics and gynecological settings have been higher compared to other specialties. Women undergoing caesarean section have 5 to 20 -fold greater risk for infection compared with vaginal delivery. Many studies reported antimicrobial prophylaxis prevent post-operative infections. Hence this study concentrates the evaluation of the prescribing antimicrobial use and to assess the frequency of post-operative morbidity related to infection in subjects undergoing caesarean section. The aim of the study was to analysis the effectiveness, prophylactic antibiotics (amoxicillin versus ceftriaxone) and to evaluate the post-operative (caesarean) infections in patients undergoing lower segment caesarean section (elective and emergency).

Methods: This is a prospective observational study which assessed the effectiveness and use of prophylactic antibiotics in patients undergoing cesarean section at department of obstetrics and gynecology. The study was conducted over a period of one year.

Results: The corresponding mean age of all the study population in amoxicillin group $(n=113)$ was $56.5 \pm 28.5$ and in ceftriaxone group ( $\mathrm{n}=97$ ) was $48.5 \pm 26.5$ respectively. The participant who underwent previous cesarean section in amoxicillin group is $65.48 \%$ similarly in ceftriaxone group is $47.42 \%$. The patients with fetal distress in ceftriaxone group are $14.77 \%$ and in amoxicillin group is $8.92 \%$. Failed induction in amoxicillin group is $9.82 \%$ and in ceftriaxone group is $6.81 \%$. The number of days in hospital stay in amoxicillin group is $42.42 \%$ and in ceftriaxone group is $45.94 \%$. The post-operative complications in amoxicillin group reported, with Febrile Illness are $40 \%$ and wound Infection is $60 \%$.

Conclusions: Administration of pre-operative antibiotics significantly reduce post-operative infections. Use of ceftriaxone as a prophylactic antibiotic in patients undergoing lower segment caesarean section (elective and emergency) is more effective than Amoxicillin in preventing post-operative infections.
\end{abstract}

Keywords: Amoxicillin, Ceftriaxone, Post-operative infections, Prophylactic antibiotics

\section{INTRODUCTION}

Women undergoing caesarean section are under higher chance for infection compared with a vaginal delivery. Many studies reported antimicrobial prophylaxis prevent post-operative infections. Postoperative endometritis is an infection caused by bacteria normally present in the host's lower genital tract. ${ }^{1}$ Prophylactic antibiotics in women undergoing caesarean delivery substantially reduced the incidence of pyrexia. Prophylactic antibiotics are administered prior to surgical incision to reduce infect ions at the surgical site. Antibiotics are frequently 
prescribed in obstetrics and gynaecological practice prophylactic during pre-operative and post-operative procedures (C-section) or to treat ongoing infections (vaginitis, endometriosis, urinary tract infection etc.). The solely use of prophylactic use of antibiotics is not to sterilize the tissue but it acts as an adjunct to decrease the intra-operative microbial load to a level which can be managed by the host innate and adaptive immune responses. ${ }^{2}$ The use of antibiotics in women for childbearing age group is important because it effects this population and there next generations.

Surgical site infections are common complication of obstetrics and gynaecological procedures. Several studies proved the use of antimicrobial prophylaxis for $\mathrm{C}$-section been effective in reducing post-operative morbidity, cost and duration of hospitalization. ${ }^{3}$ Usage of antibiotics although becoming inevitable but it should be under low level. ${ }^{4}$ Incidence of post-partum infections for both mother and neonates is prevented by prophylactic use of antibiotics. ${ }^{5}$ Hence present study was carried out to evaluate the usage of antimicrobial prophylaxis in women undergoing $\mathrm{C}$-section.

\section{METHODS}

This is prospective observational study was conducted in department of obstetrician and gynecology at NRI General Hospital, Guntur. Approximately 30-60 patients will undergo cesarean section (elective and emergency) in the department per month. The study was conducted over a period of one year from July 2018 to June 2019. The patients included in the study were patients undergoing elective and emergency lower segment cesarean section and excluded patients with patients on long term steroids, or immune suppressants, patients who are allergic to any of the drugs under study, patients who have established infections before surgery, e.g. chorioamnionitis, patients with febrile conditions of unknown etiology, patients whose data is insufficient.

After approval from the Institutional Human Ethical Committee and taking informed consent from the study subjects the relevant and necessary data were obtained using a data collection form with the following details, treatment charts and laboratory data reports and in-patient progress. All the patients were monitored from the day of admission to the day of discharge for any post-operative events that may occur after cesarean section. All the data was subjected to analysis in order to assess the effectiveness of antibiotics during cesarean section. ${ }^{5}$

\section{Statistical analysis}

The data was analyzed and the percentage value was calculated for the use of different class of antibiotics with respect to various parameters such as indication, dose, frequency and duration and time of administration of antibiotics was assessed by analyzing the collected data against standard texts, relevant literature and available antibiotic guidelines. Averages/means, standard deviations and percentages were obtained by using student t-test and Microsoft excel.

\section{RESULTS}

During the study 210 patients who underwent caesarean section were enrolled and were divided into two groups amoxicillin and ceftriaxone groups. Various parameters were evaluated for the effectiveness of the prescribed antibiotics. The study subjects in amoxicillin group with age groups $15-25$ and $25-35$ were found to be 75.22 , $24.77 \%$ respectively and in ceftriaxone group was found to be 77.31 and $22.68 \%$ respectively and there mean age of this study subjects in amoxicillin group is $56.5 \pm 28.5$ and $48.5 \pm 26.5$ in ceftriaxone group. The socio-economic status in amoxicillin group categorized as employed and unemployed are 36.28 and $63.71 \%$ respectively, similarly in ceftriaxone group it is 41.23 and $58.76 \%$.

The mean socio-economic status of this study in amoxicillin group is $56.5 \pm 15.5$ and in ceftriaxone group is $48.5 \pm 8.5$. The education level in groups standard $<10^{\text {th }}$ and above 10th standard group in amoxicillin is 53.09 and 46.90 respectively, similarly in ceftriaxone group is 61.85 and 38.14 (Table 1).

Table 1: Socio-demographic characteristic of the participants.

\begin{tabular}{|lllll|}
\begin{tabular}{|l} 
Characteristics \\
Age in years
\end{tabular} & $\begin{array}{c}\text { Amoxicillin group } \\
\text { No. of patients }(\mathbf{n = 1 1 3})\end{array}$ & $\begin{array}{l}\text { Percentage } \\
\text { No. of patients (n=97) }\end{array}$ & Percentage \\
\hline $15-25$ & & & & \\
\hline $25-35$ & 85 & $75.22 \%$ & 75 & $77.31 \%$ \\
\hline Socio-economic status & 28 & $24.77 \%$ & 22 & \\
\hline Employed & 41 & & & $41.23 \%$ \\
\hline Unemployed & 72 & $36.28 \%$ & 40 & $58.76 \%$ \\
\hline Education level & & $63.71 \%$ & 57 & $61.85 \%$ \\
\hline$<$ Standard $10^{\text {th }}$ & 60 & & & $38.14 \%$ \\
\hline$>$ Standard $10^{\text {th }}$ & 53 & $53.09 \%$ & 60 & \\
\hline
\end{tabular}


Table 2: Obstetric characteristics in the study subjects.

\begin{tabular}{|c|c|c|c|c|}
\hline \multirow{2}{*}{ Characteristics } & \multicolumn{2}{|l|}{ Amoxicillin group } & \multicolumn{2}{|l|}{ Ceftriaxone group } \\
\hline & No. of patients $(n=113)$ & Percentage & No. of patients $(n=97)$ & Percentage \\
\hline \multicolumn{5}{|c|}{ 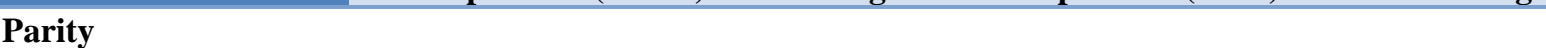 } \\
\hline 1 & 28 & $24.77 \%$ & 35 & $36.08 \%$ \\
\hline 2 & 46 & $40.70 \%$ & 35 & $36.08 \%$ \\
\hline 3 & 27 & $23.89 \%$ & 21 & $21.64 \%$ \\
\hline 4 & 8 & $7.07 \%$ & 5 & $5.15 \%$ \\
\hline 5 and $>5$ & 4 & $3.53 \%$ & 1 & $1.03 \%$ \\
\hline \multicolumn{5}{|l|}{ Gestational age } \\
\hline $25-29$ & 1 & $0.88 \%$ & - & - \\
\hline $30-34$ & 29 & $25.66 \%$ & 24 & $24.74 \%$ \\
\hline $35-39$ & 83 & $73.45 \%$ & 73 & $75.25 \%$ \\
\hline \multirow{2}{*}{ Antenatal care } & Yes & $100 \%$ & 97 & $100 \%$ \\
\hline & No & - & - & - \\
\hline \multirow{2}{*}{ Previous c-sections } & Yes $\quad 74$ & $65.48 \%$ & 46 & $47.42 \%$ \\
\hline & No 43 & $38.05 \%$ & 45 & $46.39 \%$ \\
\hline
\end{tabular}

Obstetric characteristics in the study subjects whose parity is categorized into 1-5. Majority of patients are in parity 2 followed by 1, 3, 4 and finally 5 in amoxicillin group. Majority of patients are in parity 1, 2 followed by 3,4 and 5 in ceftriaxone group. The gestational age of amoxicillin group 25-29, 30-34 and 35-39 weeks is observed as $0.88,25.66$ and $73.45 \%$, respectively and in ceftriaxone group $30-34,35-39$ is 24.74 and $75.25 \%$ (Table 2).
Out of 210 subjects, 59 reported with co-morbidities in amoxicillin group and 56 reported with co- morbidities in ceftriaxone group. Oligohydramnios condition in amoxicillin group is 10.61 and in ceftriaxone group is $11.34 \%$ gestational diabetes mellitus in ceftriaxone group is $4.42 \%$ followed by anaemia in amoxicillin group is $8.84 \%$, gestational hypertension in ceftriaxone group $9.27 \%$ and pre-eclampsia and hyperthyroidism in amoxicillin group is $5.08 \%$ and $2.65 \%$ (Table 3).

Table 3: Co-morbidities of pregnant women.

\begin{tabular}{|lllll|}
\hline \multirow{2}{*}{ Co- morbidities } & Amoxicillin group & & Ceftriaxone group & Percentage \\
\hline & No. of patients $(\mathbf{n}=113)$ & Percentage & No. of patients $(\mathbf{n = 9 7})$ & $11.34 \%$ \\
\hline Gestational DM & 5 & $4.42 \%$ & 11 & $9.27 \%$ \\
\hline Gestational HTN & 8 & $7.079 \%$ & 9 & $34 \%$ \\
\hline Oligohydramnios & 12 & $10.61 \%$ & 11 & $3.09 \%$ \\
\hline Anemia & 10 & $8.84 \%$ & 3 & $1.03 \%$ \\
\hline Scar rupture of uterus & 7 & $6.19 \%$ & 1 & $7.21 \%$ \\
\hline Pre-eclampsia & 3 & $2.65 \%$ & 7 & $6.18 \%$ \\
\hline Hypothyroidism & 8 & $7.079 \%$ & 6 & - \\
\hline Hyperthyroidism & 3 & $2.65 \%$ & - & $4.12 \%$ \\
\hline Others & 3 & $2.65 \%$ & 4 & \\
\hline
\end{tabular}

Indication for current caesarean section in study population of previous c-section of amoxicillin group is 30.35 and $26.13 \%$ in ceftriaxone group. The patients with foetal distress in ceftriaxone group are $14.77 \%$ and in amoxicillin group is $8.92 \%$. Failed induction in Amoxicillin group is $9.82 \%$ and in ceftriaxone group is $6.81 \%$. Breech presentation in amoxicillin groups is $3.57 \%$ and in ceftriaxone group is $4.56 \%$. Twin pregnancy in amoxicillin group $2.67 \%$ and $1.13 \%$ in ceftriaxone group (Table 4). The participants who reported with pyrexia in amoxicillin group is $4.42 \%$ in amoxicillin group and in ceftriaxone group is $4.12 \%$ (Table 5).
In Amoxicillin group 22.12, $27.43 \%$ and 50.44\% study subjects had c-section procedure duration 30-45 min, 45$60 \mathrm{~min}$ and 60-90 min respectively. In ceftriaxone group $50.44,31.95 \%$ and $52.57 \%$ study subjects had c-section procedure duration of 30-45 $\mathrm{min}, 45-60 \mathrm{~min}$ and $60-90$ min respectively (Table 6).

The length of hospital stays of amoxicillin group 3-5 days, 6-7 days, 8-9 days, 10-15 days is 7.07, 18.18, 42.42 and $32.32 \%$ respectively, and similarly in ceftriaxone group is $11.71,21.62,45.94$ and $20.72 \%$ respectively (Table 7). 
The post-operative event in amoxicillin group reported with febrile illness is $40 \%$ and wound infection is $60 \%$ (Table 8) whereas none of the study subjects in ceftriaxone group reported febrile illness and wound infection.

Table 4: Indication for current caesarean section.

\begin{tabular}{|lllll|}
\hline Indication & Amoxicillin group & & Ceftriaxone group & \\
& No. of patients $(\mathbf{n = 1 1 3})$ & Percentage & No. of patients $(\mathbf{n = 9 7})$ & Percentage \\
\hline Breech presentation & 4 & $3.57 \%$ & 4 & $4.56 \%$ \\
\hline Fetal distress & 10 & $8.92 \%$ & 13 & $14.77 \%$ \\
\hline Placenta Praevia & 4 & $3.57 \%$ & 1 & $1.13 \%$ \\
\hline Cephalo-pelvic disproportion & 6 & $5.35 \%$ & 6 & $6.81 \%$ \\
\hline Pregnancy induced hypertension & 5 & $4.46 \%$ & 4 & $4.54 \%$ \\
\hline Failed Induction & 11 & $9.82 \%$ & 6 & $6.81 \%$ \\
\hline $\begin{array}{l}\text { Premature ruptured membranes } \\
\text { with failed induction }\end{array}$ & 2 & $1.78 \%$ & 3 & $3.4 \%$ \\
\hline Twin Pregnancy & 3 & $2.67 \%$ & 1 & $1.13 \%$ \\
\hline Previous C/S & 34 & $30.35 \%$ & 23 & $26.13 \%$ \\
\hline Two previous c/s & 8 & $7.14 \%$ & 6 & $6.81 \%$ \\
\hline Others & 25 & $22.32 \%$ & 21 & $23.86 \%$ \\
\hline
\end{tabular}

Table 5: Post-operative fever of study subjects.

\begin{tabular}{|lllll|}
\hline Pyrexia & Amoxicillin group & & Ceftriaxone group & \\
\hline Nos & 5 & Percentage & No. of patients $(\mathbf{n = 9 7})$ & Percentage \\
\hline No & 108 & $4.42 \%$ & 4 & $4.12 \%$ \\
\hline
\end{tabular}

Table 6: Intra-operative events.

\begin{tabular}{|c|c|c|c|c|c|}
\hline \multirow{2}{*}{\multicolumn{2}{|c|}{ Characteristics }} & \multicolumn{2}{|l|}{ Amoxicillin group } & \multicolumn{2}{|l|}{ Ceftriaxone group } \\
\hline & & No. of patients $(n=113)$ & Percentage & No. of patients (n=97) & Percentage \\
\hline \multirow{3}{*}{ Type of anaesthesia } & Spinal & 113 & $100 \%$ & 97 & $100 \%$ \\
\hline & GA & - & - & - & - \\
\hline & Epidural & - & - & - & - \\
\hline \multirow{3}{*}{ Duration of surgery } & $30-45 \min$ & 25 & $22.12 \%$ & 15 & $15.46 \%$ \\
\hline & $45-60 \mathrm{~min}$ & 31 & $27.43 \%$ & 31 & $31.95 \%$ \\
\hline & $60-90 \mathrm{~min}$ & 57 & $50.44 \%$ & 51 & $52.57 \%$ \\
\hline \multirow{2}{*}{ Type of surgery } & Elective & 53 & $46.9 \%$ & 57 & $58.76 \%$ \\
\hline & Emergency & 60 & $53.09 \%$ & 40 & $41.23 \%$ \\
\hline
\end{tabular}

Table 7: Length of hospital stay.

\begin{tabular}{|lllll|}
\hline \multirow{2}{*}{ Hospital stay (days) } & Amoxicillin group & & Ceftriaxone group \\
\cline { 2 - 5 } & No. of patients $(\mathbf{n = 9 9 )}$ & Percentage & No. of patients (n=111) & Percentag \\
\hline $3-5$ & 7 & $7.07 \%$ & 13 & $11.71 \%$ \\
\hline $6-7$ & 18 & $18.18 \%$ & 24 & $21.62 \%$ \\
\hline $8-9$ & 42 & $42.42 \%$ & 51 & $45.94 \%$ \\
\hline $10-15$ & 32 & $32.32 \%$ & 23 & $20.72 \%$ \\
\hline
\end{tabular}

\section{DISCUSSION}

Postoperative infections at obstetrics and gynecology are higher when compared to other specialties. As there is higher occurrence of caesarean delivery and it is the mostly commonly performed major surgical procedures in the department of obstetrics and gynecology. This causes a significant burden in terms of patient morbidity and cost to health services around the world. ${ }^{6}$ The mean age of this study subjects in amoxicillin group is 
$56.5 \pm 28.5$ and $48.5 \pm 26.5$ in ceftriaxone group. Study data is comparable to that of Ibrahim WH et al, with the mean age $33.33 \pm 14.38 .^{7}$

The mean gestational age of this study in amoxicillin group is $37.66 \pm 34.03$ and in ceftriaxone group is $48.5 \pm 24.5$. This is agreed nearly to Prathima $S$ et al that showed the mean gestational age was $38.26 \pm 0.79 .{ }^{8}$ The participant who underwent previous c-section in amoxicillin group is $58.5 \pm 15.5$ and in ceftriaxone group is $45.5 \pm 0.5$. This finding is in agreement with Shah $\mathrm{Z}$ et al, who showed that the previous caesarean section in the study subjects was $45.15 \pm 14.46$. $^{9}$

Concerning the indication for current caesarean section previous c-section of amoxicillin group is 30.35 and $26.13 \%$ in ceftriaxone group. This is agreed nearly with Prathima $\mathrm{S}$ et al, which showed that the percent of repeated caesarean section as primary indication was $29.2 \% .^{8}$

Table 8: Post-operative events.

\begin{tabular}{|lllll|}
\hline \multirow{2}{*}{ Post-operative event } & Amoxicillin group & & Ceftriaxone group & Percentage \\
\hline Wound Infection & No. of patients $(\mathbf{n = 5})$ & Percentage & No. of patients (n=0) & - \\
\hline Endometritis & 2 & $40 \%$ & - & - \\
\hline UTI & - & - & - & - \\
\hline Pneumonia & - & - & - & - \\
\hline Febrile illness & - & - & - & - \\
\hline Others & 3 & $60 \%$ & - & - \\
\hline
\end{tabular}

Regarding the duration of surgery in amoxicillin group is $37.66 \pm 13.88$ and in ceftriaxone group is $32.33 \pm 14.72$. The findings were similar to Farouk $\mathrm{H}$ et al, who reported the duration of surgery was $38.7 \pm 13.6 .^{10}$

The incidence of post-operative febrile illness $2 \%$ and wound infection 3\% and no post-operative febrile illness and wound infection were found in cephalosporin group this results are not in agreement with Ibrahim WH et al, who reported post-operative fever was significantly higher in amoxicillin group (12\%) versus (3\%) in cephalosporin group. ${ }^{7}$ There was reduction of wound infections in cephalosporin group which is in agreement with Dlamini LD. ${ }^{11}$ Use of ceftriaxone as a prophylactic antibiotic in patients undergoing lower segment caesarean section (elective and emergency) is more effective than amoxicillin in preventing post-operative infections reduce the rates of post-operative complications like surgical site wound infection, febrile morbidity, and urinary tract infections irrespective of time of administration which can reduces the length of hospital stay that in turn increases the quality of patient care. ${ }^{12}$

\section{CONCLUSION}

Administration of preoperative antibiotics before surgery significantly reduced to post-operative infections. Use of ceftriaxone as a prophylactic antibiotic in patients undergoing lower segment caesarean section (elective and emergency) is more effective than amoxicillin in preventing post-operative infections. Based on the findings of the present study it concluded that: use of ceftriaxone as a prophylactic antibiotic in patients undergoing lower segment caesarean section (elective and emergency) is more effective than Amoxicillin in preventing post-operative infections.

Funding: No funding sources

Conflict of interest: None declared

Ethical approval: The study was approved by the Institutional Ethics Committee

\section{REFERENCES}

1. ACOG Committee on Obstetric Practice Antimicrobial prophylaxis for caesarean delivery: Timing of administration. Obstet Gynaecol. 2010;116:791-2.

2. Ansari N, Das CR Ansari MA. Evaluation of prophylactic antibiotic in caesarean section. J Nepalgunj Med Coll. 2014;12(2):40-1.

3. Lamont RF, Sobel J, Kusanovic JP, Vaisbuch E, Mazaki-Tovi S, Kim SK, et al. Current debate on the use of antibiotic prophylaxis for cesarean section. $\mathrm{Br}$ J Obstet Gynaecol. 2011;118(2):193-201.

4. Mackeen AD, Packard RE, Ota E, Berghella V, Baxter JK. Timing of intravenous prophylactic antibiotics for preventing postpartum infectious morbidity in women undergoing cesarean delivery. Cochrane Database Syst Rev. 2014;5:12

5. Jyothirmayi CA, Halde A, Yadav B, Samuel ST, Kuruvilla A, Jose R. A randomized controlled double-blind trial comparing the effects of the prophylactic antibiotic, Cefazolin, administered at caesarean delivery at two different timings (before skin incision and after cord clamping) on both the mother and newborn. BMC Preg Childbirth. 2017; 17:340. 
6. Smaill FM, Grivell RM. Antibiotic prophylaxis versus no prophylaxis for preventing infection after caesarean section. Cochrane Database Syst Rev. 2014;110:123-4.

7. Ibrahim WH, Makhlouf AM. Effect of prophylactic antibiotics (Cephalosporin versus Amoxicillin) on preventing post caesarean section infection. J Am Sci. 2011;7(5):178-87.

8. Prathima S, Savitha C, Tejeswini KK. Comparative study of single dose versus multiple doses of antibiotic prophylaxis in caesarean delivery. Inter $\mathbf{J}$ Reprod Contracept Obstet Gynaecol. 2017;6(1):2158.

9. Zeel Shah, Kshirsagar NS, Shah S. Comparison of single dose prophylactic antibiotics versus five days antibiotic in caesarean section. J Evol Med Dent Sci. 2014;3(12):3123-9.

10. Farouk H, El Fatah AA, Gaber A. Single dose prophylactic antibiotic before skin incision (suggested regimen prior to elective cs in al-zahraa hospital). Al-Azhar Assuit Med J. 2011;9(1):46-62.
11. Dlamini LD, Sekikubo M, Tumukunde J, Kojjo C, Ocen D, Wabule A, et al. Antibiotic prophylaxis for caesarean section at a Ugandan hospital: a randomised clinical trial evaluating the effect of administration time on the incidence of postoperative infections. BMC Preg Childbirth. 2015;15(1):91.

12. Kumari R, Sharma A, Sheetal, Roy P. To study the effectiveness of prophylactic use of ceftriaxone (single dose) in caesarean section in low risk patients in a tertiary care centre, Moradabad, India. Inter $\mathbf{J}$ Res Med Sci. 2017;5(12):5278-82.

Cite this article as: Lingam KR, Ramineni HB, Firdous SG, Yamuna P, Madhuri B, Chidrupi DNSS. Effectiveness and use of prophylactic antibiotics in elective and emergency caesarean section at tertiary care hospital. Int J Reprod Contracept Obstet Gynecol 2020;9:2053-8. 